\title{
Análise in vitro da desinfecção de escovas dentais por substâncias com potencial antimicrobiano
}

\author{
In vitro analysis of toothbrushes' disinfection by antimicrobial activity substances
}

Análisis in vitro de la desinfección de cepillos dentales por sustancias con potencial antimicrobiano

\author{
Erick Tássio Barbosa NEVES ${ }^{1}$ \\ Erik Lafitt Tavares MONTEIRO' \\ Diego Romário SILVA ${ }^{2}$ \\ Matheus França PERAZZO 3 \\ Zilka Nanes LIMA 4 \\ Alessandro Leite CAVALCANTI ${ }^{1}$
}

${ }^{1}$ Departamento de Odontologia, Universidade Estadual da Paraíba - UEPB, 58429-500, Campina Grande-PB, Brasil

${ }^{2}$ Departamento de ciências fisiológicas (Farmacologia, Anestesiologia e Terapêutica) Faculdade de Odontologia de Piracicaba-FOP/UNICAMP, Universidade Estadual de Campinas, 13414-018, Piracicaba-SP, Brasil

${ }^{3}$ Departamento de Odontologia, Universidade Federal de Minas Gerais - UFMG, 31270-901, Belo Horizonte-MG, Brasil

${ }^{4}$ Departamento de Farmácia, Universidade Estadual da Paraíba - UEPB, 58429-500, Campina Grande-PB, Brasil

\section{Resumo}

Introdução: a correta utilização de técnicas e materiais de higiene são alguns dos fatores que influenciam positivamente a saúde bucal. O mal acondicionamento e higienização das escovas dentais podem contribuir para a reincidência de infecções bucofaríngeas. Objetivo: avaliar, in vitro, o potencial de descontaminação de duas diluições de hipoclorito de sódio em escovas dentais. Materiais e Métodos: as escovas foram inoculadas com Escherichia coli, Candida albicans, Streptococcus mutans e Pseudomonas aeruginosa, durante 30 segundos. Posteriormente foram tratadas por 10 minutos com: solução bucal Colgate Periogard® com álcool e 0,12\% de gluconato de clorexidina, Água Sanitária Brilux ${ }^{\circledR} \operatorname{com} 2,5 \%$ de cloro ativo diluída em água destilada até a concentração de $1 \%$ e Água Sanitária Brilux® com $2,5 \%$ de cloro ativo diluída em água destilada de acordo com a indicação do fabricante para desinfecção de frutas e vegetais $(0,005 \%)$. Alíquotas das soluções foram semeadas em BHI ágar e incubadas a $37^{\circ} \mathrm{C}$, por 48 horas. Foi feita a contagem das Unidades Formadoras de Colônia UFC/mL. Resultados: para as soluções Colgate Periogard® e Água Sanitária Brilux® (1\%) não foi observado crescimento de microrganismos, já a solução Sanitária Brilux ${ }^{\circledR}(0,005 \%)$ apresentou um discreto crescimento para Streptococcus mutans (10200 UFC/ml) e Candida albicans(1200 UFC/ml). Conclusão: o Colgate Periogard® e a Água Sanitária Brilux® (1\%) foram semelhantemente eficazes na desinfecção das escovas. O hipoclorito é uma substância de baixo custo, de fácil acesso e um bom candidato a ser adotado para a indicação de armazenamento e limpeza das escovas.

Descritores: Anti-Infecciosos; Desinfecção; Escovação Dentária.

\section{Abstract}

Introduction: The correct use of techniques and hygiene materials are some of the factors that positively influence oral health. Poorly conditioned and hygienised toothbrushes may contribute to the recurrence of oropharyngeal infections. Objective: to evaluate, in vitro, the decontamination potential of two dilutions of sodium hypochlorite in dental brushes. Materials and Methods: The brushes were inoculated with Escherichia coli, Candida albicans, Streptococcus mutans and Pseudomonas aeruginosa for 30 seconds. They were then treated for 10 minutes with: Colgate Periogard $₫$ alcohol solution and $0.12 \%$ chlorhexidine gluconate, Brilux ${ }^{\circledR}$ Sanitary Water with $2.5 \%$ active chlorine diluted in distilled water to a concentration of $1 \%$ and Sanitary Water Brilux ${ }^{\circledR}$ with $2.5 \%$ active chlorine diluted in distilled water according to the manufacturer's indication for disinfection of fruits and vegetables $(0.005 \%)$. Aliquots of the solutions were seeded in BHI agar and incubated at $37{ }^{\circ} \mathrm{C}$ for 48 hours. The UFC / mL colony forming units were counted. Results: Brilux® solution $(0,005 \%)$ showed a slight growth for Streptococcus mutans (10200 CFU / ml) and Candida albicans (1200 CFU / ml). Conclusion: Colgate Periogard ${ }^{\circledR}$ and Brilux ${ }^{\circledR}$ Sanitary Water $(1 \%)$ were similarly effective in disinfecting the brushes. Hypochlorite is a low cost, easily accessible substance and a good candidate to be adopted for the storage and cleaning indication of brushes.

Descriptors: Anti-Infective Agents; Desinfection; Toothbrushing.

\section{Resumen}

Introducción: la correcta utilización de técnicas y materiales de higiene son algunos de los factores que influencian positivamente la salud bucal. El mal acondicionamiento e higienización de los cepillos dentales pueden contribuir a la reincidencia de infecciones bucofaríngeas. Objetivo: evaluar, in vitro, el potencial de descontaminación de dos diluciones de hipoclorito de sodio en cepillos dentales. Materiales y Métodos: los cepillos fueron inoculados con Escherichia coli, Candida albicans, Streptococcus mutans y Pseudomonas aeruginosa, durante 30 segundos. En la mayoría de los casos, se observó un aumento en la concentración de agua potable en el agua potable, con una concentración de $1 \%$ y agua sanitaria, Brilux ${ }^{\circledR}$ con $2,5 \%$ de cloro activo diluida en agua destilada de acuerdo con la indicación del fabricante para desinfección de frutas y vegetales $(0,005 \%)$. Las alícuotas de las soluciones fueron sembradas en $\mathrm{BHI}$ ágar e incubadas a $37^{\circ} \mathrm{C}$, por 48 horas. Se realizó el conteo de las Unidades Formadoras de Colonia UFC / mL. Resultados: para las soluciones Colgate Periogard ${ }^{\circledR}$ y Agua Sanitaria Brilux ${ }^{\circledR}(1 \%)$ no se observó crecimiento de microorganismos, ya la solución Sanitaria Brilux ${ }^{\circledR}(0,005 \%)$ presentó un discreto crecimiento para Streptococcus mutans (10200 UFC / ml) y Candida albicans (1200 UFC / ml). Conclusión: el Colgate Periogard® y el Agua Sanitaria Brilux® (1\%) fueron similares en la desinfección de las escobillas. El hipoclorito es una sustancia de bajo costo, de fácil acceso y un buen candidato a ser adoptado para la indicación de almacenamiento y limpieza de los cepillos.

Descriptores: Antiinfecciosos; Desinfección; Cepillado Dental.

\section{INTRODUÇÃO}

A higiene bucal está relacionada à diminuição da prevalência da cárie dental, como também à saúde gengival adequada, estética e a relação social do indivíduo. Para sua manutenção, considera-se que o controle mecânico do biofilme dental (escovas, fio dental e enxaguatórios bucais) é um método fácil e eficaz, de forma que a utilização de protocolos de higiene baseado nesses itens impacta positivamente na saúde bucal dos pacientes $^{1,2}$.

Os primeiros relatos oficiais de que escovas dentais poderiam atuar como uma fonte de infecções repetidas por via oral são encontrados no início do século $\mathrm{XX}^{3}$. Em seguida, surgiram discussões acerca 
de uma condição sistêmica mais complicada, a endocardite bacteriana resultante de bacteremia por escovas dentais contaminadas ${ }^{4}$.

Recomenda-se que as escovas dentais sejam substituídas mensalmente e armazenadas de forma adequada durante o seu uso, pois proporcionam um meio contaminado, juntamente ao substrato de restos alimentares, favorecendo o crescimento de microrganismos. Nesse sentido, a utilização de substâncias desinfetantes em intervalos regulares pode contribuir para redução dessas contaminações ${ }^{5,6}$.

A maioria dos microrganismos transferidos da escova dental para a cavidade bucal ou para outras escovas (quando acondicionadas no mesmo ambiente) compõem a microbiota natural do paciente, no entanto, na presença de quadros infecciosos, é possível que os microrganismos envolvidos também sejam transferidos ${ }^{7,8}$.

A literatura tem demostrado melhor recuperação de pacientes com infecções bucofaríngeas após a substituição das escovas dentais usadas por outras novas, indicando potencialização na capacidade de resposta do hospedeiro que realizou a substituição em relação àqueles que não realizaram?.

A partir dessa perspectiva, é importante que sejam desenvolvidos estudos para análise de substâncias capazes de promover a desinfecção de escovas dentais. Tal proposta é particularmente positiva devido à possibilidade de utilização dos agentes desinfetantes em âmbito coletivo, com um destaque para o ambiente pré-escolar, quando hábitos de higiene geral são introduzidos e a possibilidade de infecções pelo amplo contato é claramente maior ${ }^{10}$. Assim, o objetivo desse trabalho foi analisar agentes químicos de custo acessível para desinfecção de escovas dentais.

\section{MATERIAL E MÉTODO}

\section{Descrição do estudo}

A análise foi realizada no laboratório de análises clínicas da Universidade Estadual da Paraíba (UEPB). A amostra foi composta por 100 escovas dentais pop 32 macias (Bitufo®). As escovas foram divididas em quatro grupos de 25 escovas. Cada grupo foi contaminado com uma espécie de microrganismo que pode ser encontrado no ambiente bucal.

Inoculação das escovas

Foram utilizadas cepas de quatro microrganismos: Escherichia coli (E. coli) ATCC 25922, Pseudomonas aeruginosa ( $P$. aeruginosa) ATCC 15442, Streptococcus mutans (S. mutans) ATCC 25175 e Cândida albicans (C. albicans) ATCC 289065. Cada grupo, contendo 25 escovas, foi imerso, por 30 segundos, em um tubo de ensaio contendo o inóculo de um dos microrganismos diluído em solução salina a $0,9 \%$. A concentração de células presentes na solução contaminada foi padronizada em uma escala de $1,5 \times 10^{8}$ células (Escala MacFarland).

\section{Desinfecção das escovas}

Após imersão no inóculo, as escovas foram transportadas para tubos de ensaio contendo $10 \mathrm{ml} \mathrm{de}$ diferentes agentes químicos, onde permaneceram durante por 10 minutos. De cada grupo de 25 escovas, cinco tiveram suas cerdas submersas em hipoclorito de sódio (água sanitária Brilux ${ }^{\circledR}$ com $2,5 \%$ de cloro ativo diluída em água destilada até a concentração de $1 \%$ ), outras cinco em água sanitária Brilux ${ }^{\circledR}$ com $2,5 \%$ de cloro ativo diluída em água destilada de acordo com a indicação do fabricante para desinfecção de frutas e vegetais $(10 \mathrm{ml}$ de solução para cada 5 litros de água destilada $-0,005 \%$ de cloro ativo) e as cinco restantes em solução bucal de clorexidina a $0,12 \%$ (Colgate Periogard® - CLX).

As escovas foram previamente esterilizadas em solução de gluteraldeído 2,5\%. O controle positivo foi o grupo de escovas tratadas com glutaraldeído. Com relação às cinco escovas do controle negativo, logo após contaminação no inóculo foram submersas em solução fisiológica estéril.

\section{Plaqueamento das amostras}

Após sua imersão em tubos de ensaio com os agentes químicos, as escovas foram encaminhadas para descarte $\mathrm{e}$ as soluções resultantes foram semeadas em placas de Petri com BHI Agar (Agar Infusão de Cérebro e Coração Modelo M211). O $S$. mutans foi cultivado em Agar sangue. A leitura dos resultados foi feita 48 horas após o semeio das placas que ficaram em estufa a $37 \mathrm{C}^{\circ}$. A placa contendo $S$. mutans foi incubada em microaerofilia. Os resultados foram obtidos em número de Unidades Formadoras de Colônia (UFC) de cada placa, obtidos por um único examinador previamente treinado, determinando a média de crescimento em cada grupo. Análise estatística

Os ensaios foram realizados em triplicata e em três experimentos independentes. Posteriormente, utilizou-se análise de variância e análise post-hoc de acordo com o teste de Tukey, com nível de significância de $5 \%(\alpha<0,05)$.

\section{RESULTADOS}

Os resultados (Figuras 1 a 4 ) mostraram superioridade dos agentes químicos: água sanitária Brilux ${ }^{\circledR}$ a $1 \%$ e da solução bucal Colgate Periogard ${ }^{\circledR}$, que possui gluconato de clorexidina a $0,12 \%$ em sua composição. A água sanitária Brilux ${ }^{\circledR}$ diluída segundo indicações do fabricante na concentração de $0,005 \%$, mostrou-se a menos eficaz das soluções para Streptcoccus mutans e Cândida albicans, embora tenha apresentado bom resultado geral nas escovas contaminadas por Escherichia coli e Pseudomonas aeruginosa. 


\section{DISCUSSÃO}

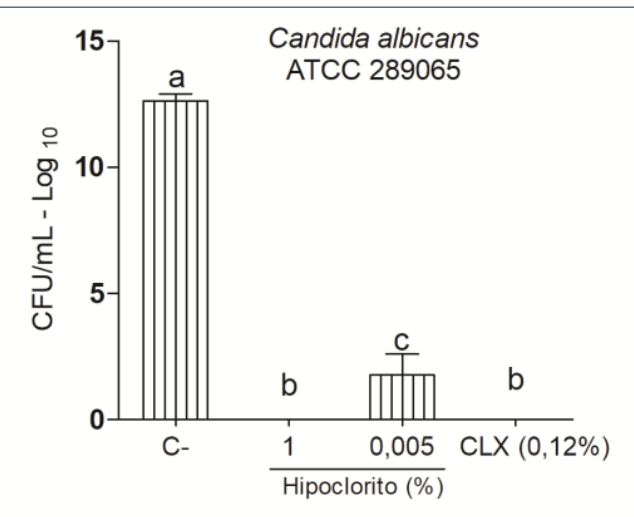

Figura 1: Gráfico mostrando a diferença entre a quantidade de $\mathrm{UFC} / \mathrm{ml}$ de $P$. Aeruginosa frente ao tratamento com diluições de hipoclorito e enxaguante bucal com clorexidina $0,012 \%$ em relação ao controle negativo.

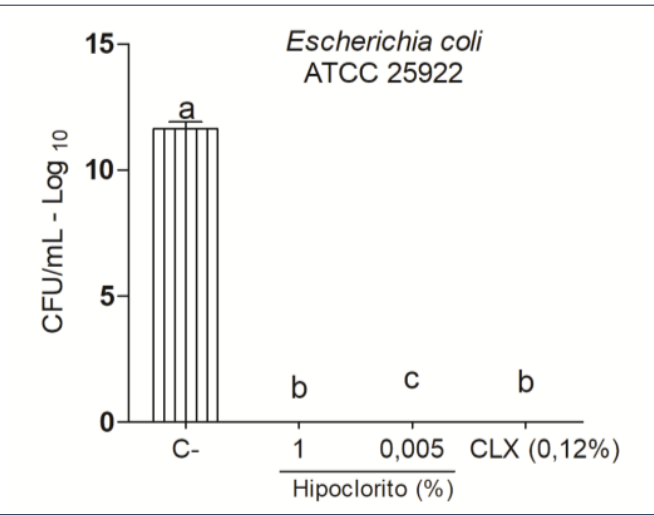

Figura 2: Gráfico mostrando a diferença entre a quantidade de UFC/ml de $S$. mutans frente ao tratamento com diluições de hipoclorito e enxaguante bucal com clorexidina $0,012 \%$ em relação ao controle negativo.

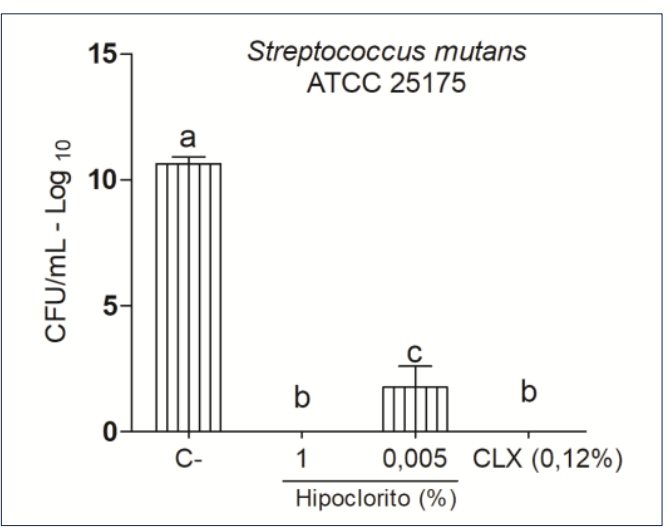

Figura 3: Gráfico mostrando a diferença entre a quantidade de UFC/ml de $E$. Coli frente ao tratamento com diluições de hipoclorito e enxaguante bucal com clorexidina $0,012 \%$ em relação ao controle negativo.

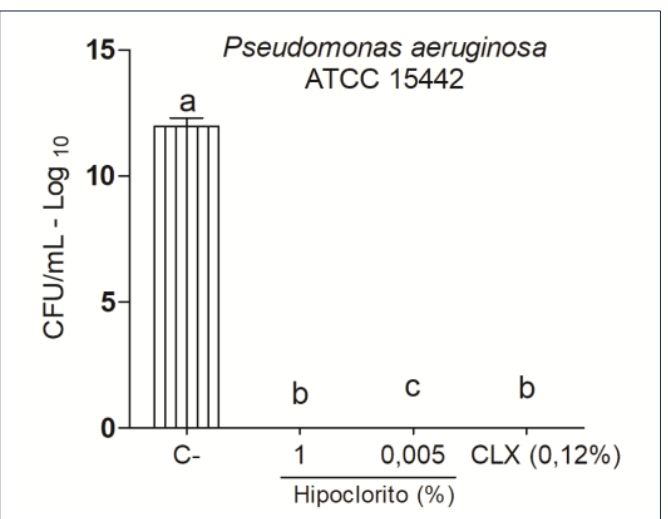

Figura 4: Gráfico mostrando a diferença entre a quantidade de UFC/ml de $C$. albicans frente ao tratamento com diluições de hipoclorito e enxaguante bucal com clorexidina $0,012 \%$ em relação ao controle negativo.
A boca é um ambiente propício à contaminação e infecção devido à presença de um elevado número de microrganismos. Frente à microbiota natural, desequilíbrios podem favorecer a proliferação desordenada de espécies oportunistas o que leva ao aumento da patogenicidade e ao estabelecimento de infecções que podem surgir localmente ou em estruturas distantes como são os casos das endocardites infecciosas e das infecções respiratórias ${ }^{11,12}$.

De forma geral, há escassa discussão em torno da desinfecção de escovas dentais. Até mesmo no ambiente acadêmico, tem-se percebido que parte dos estudantes de Odontologia não adotam uma técnica apropriada de acondicionamento e higienização das escovas dentais. Esse comportamento prejudica o processo de educação em saúde bucal, uma vez que os futuros profissionais também são responsáveis pela disseminação da informação para a população ${ }^{13}$.

A utilização de agentes químicos com a finalidade de promover a desinfecção de escovas dentais tem se popularizado, inclusive devido à existência no mercado de uma grande variedade de produtos com potencial bactericida. De modo geral, um agente para desinfecção deve favorecer o controle das infecções provocadas pela contaminação nas escovas dentais, além de apresentar baixo custo e ser de fácil acesso ${ }^{14}$.

Embora o enxágue das escovas dentais em água corrente seja um método habitual, não apresenta eficácia comprovada ${ }^{15}$. Métodos de desinfecção alternativos têm sido estudados, a exemplo da aplicação de agentes fitoterápicos. Estudo utilizando infusão de romã para desinfecção de escovas dentais contaminadas por $S$. mutans demonstrou a inefitividade dessa solução, especialmente quando comparada ao hipoclorito de sódio a $1 \%$ e ao diglucontato de clorexidina a $0,12 \%{ }^{16}$.

Com o objetivo de avaliar a contaminação e descontaminação de escovas dentais utilizadas por crianças com necessidades especiais, foi realizado um estudo experimental com três diferentes agentes químicos, que foram borrifados nas escovas dentais previamente utilizadas por 30 crianças durante 30 dias. Foram aplicadas soluções de hipoclorito de sódio a $1 \%$, diglugonato de clorexidina a $0,12 \%$ e água destilada como grupo controle. Os resultados mostraram eficiência na redução dos bacilos gram negativos e das leveduras do grupo Candida spp apenas através do uso da clorexidina, e nenhuma das soluções se mostrou efetiva contra Streptococcus spp ${ }^{17}$.

Em contraste, o presente estudo utilizou a técnica de imersão das escovas em substituição ao borrifamento, por acreditar que a primeira permite um maior contato das cerdas para ação do agente 
químico utilizado. Por essa razão sugere-se que os resultados inibitórios obtidos com a clorexidina $0,12 \%$, inclusive para $S$. mutans, podem ter se dado em decorrência dessa mudança metodológica. A ação do digluconanato de clorexidina a $0,12 \%$ foi confirmada através da imersão de escovas dentais previamente contaminadas em um outro estudo, demonstrando concordância com os resultados obtidos na presente análise ${ }^{18}$.

Em um estudo realizado com escovas de préescolares de 6-7 anos, utilizadas por cinco dias, concluiu-se que entre o borrifamento das escovas com água deionizada esterilizada, hipoclorito de sódio a $1 \%$ e ácido acético a $0,5 \%$ para sua desinfecção, a solução que mostrou maior efetividade antimicrobiana foi o hipoclorito de sódio a $1 \%{ }^{15}$. Apesar da variação metodológica devido ao uso de borrifamento, os resultados obtidos estão em concordância com $\mathrm{o}$ presente estudo, pois $\mathrm{o}$ hipoclorito de sódio em uma concentração de $1 \%$ mostrou efetividade contra os microrganismos testados.

Outras possibilidades de desinfecção de escovas vêm sendo estudadas. A utilização de dentrifícios com triclosan demonstrou uma redução significativa da contaminação de escovas dentais contaminadas pelo $S$. mutans ${ }^{19}$. Alternativas ao uso da clorexidina como agente para desinfecção também estão divulgadas na literatura. Um recente estudo demonstrou uma maior efetividade da utilização de raios ultravioleta na desinfecção de escovas em relação ao digluconato de clorexidina. Tais resultados são promissores, mas a depender do público a que se destinam podem demandar gastos inviáveis e reduzir a abrangência de indivíduos com acesso a esse recurso ${ }^{20}$.

O presente trabalho, por se tratar de estudo laboratorial, apresenta limitações próprias que evidenciam a necessidade de uma reprodução mais fidedigna do ambiente bucal. Os resultados são portanto preliminares, e acredita-se que a principal contribuição está em torno da possibilidade de permitir a avaliação de substâncias como o hipoclorito de sódio que é de baixo custo e fácil acesso populacional. Desta forma, sugere-se a realização de novos estudos utilizando escovas dentais contaminadas in vivo e prosseguimento dos pacientes para acompanhamento do nível de contaminação das escovas e melhor esclarecimento dos resultados.

\section{CONCLUSÃO}

Dentre os agentes químicos testados, a clorexidina a $0,12 \%$ apresentou os melhores resultados devido ao seu alto potencial antimicrobiano e sua baixa toxicidade em níveis controlados além de ser considerada uma substância tolerável aos tecidos bucais. O uso do hipoclorito de sódio a $1 \%$ também demonstrou resultados positivos. Cabe, no entanto, salientar o impasse que é a sua toxicidade quando em contato direto com os tecidos bucais estando em altas concentrações. Por isso recomenda-se o uso do mesmo em menores concentrações de forma a superar essa problemática e prosseguir com o enxágue completo da escova dental após a realização de todo processo de desinfecção. Recomenda-se o empenho e dedicação para um bom acondicionamento das escovas dentais em local arejado e livre de contaminação e a sua substituição periódica.

\section{REFERENCIAS}

1. Alves DM, Santos AA, Santos TJ, Bomfim AMA, Calado AA. Avaliação da eficácia de uma escova e fita dentais alternativas utilizadas na higienização bucal em escolares da rede pública. Odontol clín-cient. 2003. 2(3):191-95.

2. Murray J, Scholten I. An oral hygiene protocol improves oral health for patients in inpatient stroke rehabilitation. Gerodontology. 2018; 35(1):18-24.

3. Cobb CM. Toothbrushes as a cause of repeated infections of the mouth. Boston Med Surg J. 1920; 183:263-64.

4. Warren DP, Goldschimidt MC, Thompson MB, Adler-Storthz K, Keene WJ. The effects of toothpastes on the residual microbial contamination of toothbrushes. J Am Dent Assoc. 2001; 132(9):1241-45.

5. Moreira ACS, Cavalcante GM. Influência da higienização na contaminação de escovas dentais. Arq Ciênc Saúde Unipar. 2008; 12(2):99-103.

6. Naik R, Ahmed Mujib BR, Telagi N, Anil BS, Spoorthi BR. Contaminated tooth brushespotential threat to oral and general health. J Family Med Prime Care. 2015; 4(3):444-48.

7. Chibebe Jr J, Pallos D. Avaliação da esterilização de escovas dentais em forno de micro-ondas (estudo in vitro). Rev biociênc. 2001; 7(2):39-42.

8. Kosay K, Iway T, Miura K. Residual contamination of toothbrushes by microorganisms. ASDC J Dent Child. 1989; 56(3):201-4.

9. Glass RT. Toothbrush types and retention of microoganisms: how to choose a biologically sound toothbrush. J Okla Dent. Assoc. 1992; 82(3):26-8.

10.Massoni ACLT, Silva MCA, Perazzo MF, Pereira RVS, Pessoa CP, Granville-Garcia AF. Condições físicas e acondicionamento de escovas dentais de pré-escolares. Arq Odontol. 2015; 51(2):96-103.

11.Lockhart PB, Brennan M, Thornhill M, Michalowicz BS, Noll J, Bahrani-Mougeot FK et al. Poor oral hygiene as a risk for infective endorcaditis - related bacteremia. J Am Dent Assoc. 2009; 140(10):1238-44. 
CONFLITO DE INTERESSES

Os autores declaram não haver conflitos de interesse. disease and the role of oral bacteria. J Oral Microbiol. 2010; 2:10.3402.

13.Zão EJR, Silva MAM, Alves MU. Desinfecção e armazenamento de escovas dentais: avaliação da prática realizada por acadêmicos do Curso de Odontologia da Universidade Severino Sombra Vassouras/RJ. Rev Pró-UniverSUS. 2011; 2:53-64.

14.Gonçalo CS, Mialhe FL. Contaminação das escovas dentais: Uma revisão crítica da literatura. R Periodontia. 2009; 19(3):56-63.

15. Chaves RAC, Ribeiro DML, Zaia JE, Alves EG, Souza MGM, Martins CHG et al. Avaliação de soluções antibacterianas na descontaminação de escovas dentais de pré-escolares. Rev Odontol UNESP. 2007; 36(1):29-33.

16. Freire PLN, Campos PH, Carvalho FG, Rodrigues JA, Diniz MB. Is pomegranate peels infusion effective for disinfection of toothbrushes? Rev Odontol Unesp. 2016: 45(5):253-57.

17. Chibinsk ACR, Grando K, Fanchin PT, Campagnoli E, Santos FA, Wambier DS. Descontaminação de escovas dentais utilizadas por crianças portadoras de necessidades especiais: análise microbiológica. RSBO.2011; 8(2):145-52.

18. Soares DGS, Oliveira CB, Leal C, Drumond MRS, Padilha WWN. Atividade antibacteriana in vitro da tintura de aroeira (schinusterebinthifolius) na descontaminação de escovas dentais contaminadas pelo S. mutans. Pesq Bras Odontoped Clin Integr. 2007; 7(3):253-57.

19.Nelson-Filho P, Isper AR, Assed S, Faria G, Ito IY. Effect of triclosan dentifrice on toothbrush contamination. Pediatr Dent. 2004; 26(1):11-6.

20.Tomar P, Hongal S, Saxena V, Jain M, Rana K, Ganavadiya R. Evaluating sanitization of toothbrushes using ultra violet rays and $0.2 \%$ chlorhexidine solution: A comparative clinical study. J Basic Clin Pharm. 2014; 6(1):12-8.
Submetido em 17/07/2018

Aceito em 04/10/2018
Erick Tássio Barbosa Neves

erick.tassio@hotmail.com

\section{AUTOR PARA CORRESPONDENCIA}

